Proc. Indian Acad. Sci. (Chem. Sci.), Vol. 96, Nos 1 \& 2, January 1986, pp. 67-71.

(C) Printed in India.

\title{
Reinvestigation of the antifungal activities of some aromatic N-oxides
}

\author{
ARABINDA RAY*, S K NOOR MOHAMMAD $\dagger$, and \\ G V KULKARNI
}

\author{
Department of Chemistry, Sardar Patel University, Vallabh Vidyanagar, Gujarat 388120 , \\ India \\ † Department of Physics, Indian Institute of Technology, Kharagpur 721 302, India \\ $\mp$ Department of Inorganic and Physical Chemistry, Indian Institute of Science, \\ Bangalore 560012, India
}

MS received 15 April 1985; revised 3 July 1985

\begin{abstract}
Dinitroquinoline-N-oxide, 4-nitroquinoline $\mathrm{N}$-oxide and a series of 4-substituted pyridine $\mathrm{N}$-oxides have been subjected to MINDO/ 3 treatment in order to understand their antifungal activities. The photoelectron spectra and the nature of the $\mathrm{N}$-oxide bond are discussed.
\end{abstract}

Keywords. Antifungal activities; MINDo/3 calculation; photoelectron spectra.

\section{Introduction}

The antifungal activities of 4-nitropyridine $\mathrm{N}$-oxide, its 2-methyl derivative and 4-nitroquinoline $\mathrm{N}$-oxide have been recognised long ago (Ochiai 1967). Experimental evidence also suggests that the presence of the nitro group in these $\mathbf{N}$-oxides is essential for them to have any meaningful antifungal activity (Dodd and Stillman 1944).

The first attempt to correlate antifungal activity with nucleophilic superdelocalisability of the carbon [designated as C(4)] atom attached to the nitro group was due to Fukui et al (1960). Appreciating the ambiguity associated with the results of simple Huckel $\pi$-calculations, particularly for polar molecules like $\mathrm{N}$-oxides, Kulkarni et al (1981) did all-valence calculations like the iterative extended Huckel (IEH) and MINDO/2 for these $\mathrm{N}$-oxides. Their study could explain the electronic transitions, photoelectron spectral data etc. reasonably well, although it is rather inconclusive regarding the mechanism of the antifungal activity of the $\mathrm{N}$-oxides. Moreover, the shortcomings of the MINDO/2 method have been realised by Bingham et al (1975) who have further improved upon this version of MINDO approximation to MINDO/3, which by all means is a superior SCF method.

With this background, it becomes essential that the findings of Kulkarni et al (1981) be assessed. It is thus necessary that we reinvestigate these $\mathrm{N}$-oxides employing MINDO/3, whose results will obviously be more meaningful. One of the manifold purposes of this study is to understand why the presence of the nitro group is so vital to the antifungal activity of these $\mathrm{N}$-oxides. For this purpose we have applied the MINDO/3 calculations to pyridine, pyridine- $\mathrm{N}$-oxide, quinoline, quinoline- $\mathrm{N}$-oxide,

\footnotetext{
" To whom all correspondence should be addressed.
} 
4- $\mathrm{CN} / \mathrm{OH} / \mathrm{NH}_{2}$ pyridine- $\mathrm{N}$-oxide and dinitroquinoline- $\mathrm{N}$-oxide, in addition to 4-nitropyridine- $\mathbf{N}$-oxide and 4-nitroquinoline- $\mathbf{N}$-oxide which are proven antifungal compounds. It is also aimed at providing an insight into the mechanism of the antifungal activity of these compounds. In addition, the nature of the $\mathrm{N}$-oxide bond has also been discussed.

The energies of occupied orbitals are also compared with the photoelectron spectral data, where available, to judge the reliability of the numerical values obtained from the MINDO/ 3 calculation. All the results of the present study are compared with the findings of earlier authors (Fukui et al 1960; Kulkarni et al 1981).

\section{Method of calculation}

The semi-empirical parameters for the MINDO/3 method were taken from Bingham et al (1975), without any modification. The structural parameters, where available, were taken from X-ray data (Eichhorn 1956; Ulku et al 1971) and otherwise, were transferred from related molecules. In the absence of optimisation, it was essential to keep the lengths of similar bonds, and the magnitudes of comparable angles, constant in all molecules, so that the change of electronic environment due to the variation of functional groups mainly influences the orbital energies.

\section{Results and discussion}

\subsection{Photoelectron spectra and orbital energies}

The ionisation energies obtained from MINDO/3 calculations are compared with the observed uV photoelectron spectral data in table 1.

The photoelectron (PE) spectra of pyridine-N-oxide and a number of substituted derivatives have been reported by Weiner and Lattman (1974) and by Maier and Muller (1974). These two reports, however, have provided different assignments for the first and second ionisation processes in pyridine- $\mathrm{N}$-oxide. The PE band observed at $8.38 \mathrm{eV}$ for this compound has been assigned (Weiner and Lattman 1974) to ionisation from the highest occupied $\sigma$-MO (mainly from oxygen), while Maier and Muller (1974) assigned this to the highest occupied $\pi$-Mo. The results of the present investigation agree with Maier and Muller's view. This band (calcd. at 9.01 eV) corresponds to the highest occupied $\pi$-mo having a major contribution from the $\mathrm{O}$-atom. It is interesting to note that like pyridine-N-oxide, in all its derivatives studied, the highest occupied molecular orbitals (номо) are of the $\pi$-type having a major contribution from the oxygen of the $\mathrm{N}$ oxide moiety, with varying degrees of contribution from the ring atoms. The latter affect the номо energy substantially. However, for 4-NH $\mathrm{NH}_{2}$ PNO, (PNO-pyridine-Noxide), contributions from the $\mathrm{N}$ atom of the $-\mathrm{NH}_{2}$ group and the oxygen of the $\mathrm{N}$ oxide moiety are comparable; this factor has considerably lowered the energy of the HOMO for this molecule, compared to the others in this series. In most of these PNO compounds, a fairly invariant bond at $\approx 10.30 \mathrm{eV}$ due to the $\pi$-electrons of the ring carbon atoms is obtained from the calculation. This band however, appears at $10.85 \mathrm{eV}$ in $4 \mathrm{NO}_{2} \cdot \mathrm{PNO}$. The present assignments do not differ much from those of Kulkarni et al (1981). 
Table 1. Ionization energies (eV).

\begin{tabular}{|c|c|c|c|c|c|}
\hline Compound & Method & $I_{1}^{*}$ & $I_{2}$ & $I_{3}$ & $I_{4}$ \\
\hline \multirow[t]{2}{*}{ Pyridine } & Obs. & $9 \cdot 26$ & 10.50 & $12 \cdot 27$ & $13 \cdot 0$ \\
\hline & MINDO/3 & $\begin{array}{l}8: 54 \\
(\sigma)\end{array}$ & $\begin{array}{c}9 \cdot 18 \\
\left(\pi^{C}\right)\end{array}$ & $\begin{array}{c}9.81 \\
\left(\pi^{C, N}\right)\end{array}$ & $\begin{array}{c}10 \cdot 39 \\
(\sigma)\end{array}$ \\
\hline \multirow[t]{2}{*}{ PNO** } & Obs. & $8 \cdot 38$ & $9 \cdot 22$ & $10-18$ & 11.59 \\
\hline & MINDO/3 & $\begin{array}{r}9.01 \\
\left(\pi^{\circ}\right)\end{array}$ & $\begin{array}{c}9.87 \\
\left(\sigma^{0}\right)\end{array}$ & $\begin{array}{c}10-34 \\
\left(\pi^{C}\right)\end{array}$ & $\begin{array}{c}11 \cdot 13 \\
(\sigma)\end{array}$ \\
\hline \multirow[t]{2}{*}{$4 C N \cdot P N O$} & Obs. & 8.95 & 9.74 & $10-84$ & $11 \cdot 58$ \\
\hline & MINDO/3 & $\begin{array}{c}8.95 \\
\left(\pi^{0}\right)\end{array}$ & $\begin{array}{l}9.98 \\
(\sigma)\end{array}$ & $\begin{array}{c}1009 \\
(\sigma)\end{array}$ & $\begin{array}{c}10-35 \\
\left(\pi^{C}\right)\end{array}$ \\
\hline \multirow[t]{2}{*}{$4 \mathrm{NO}_{2} \cdot \mathrm{PNO}$} & Obs. & 9.03 & 9.80 & $10-81$ & $11 \cdot 26$ \\
\hline & MINDO/3 & $\begin{array}{r}9.71 \\
\left(\pi^{\circ}\right)\end{array}$ & $\begin{array}{c}10-65 \\
(\sigma)\end{array}$ & $\begin{array}{c}10-66 \\
(\sigma)\end{array}$ & $\begin{array}{c}10.85 \\
\left(\pi^{C}\right)\end{array}$ \\
\hline $4 \mathrm{NH}_{2} \cdot \mathrm{PNO}$ & MINDO/3 & $\begin{array}{c}8.04 \\
\left(\pi^{\mathrm{O}, N}\right)\end{array}$ & $\begin{array}{l}9 \cdot 70 \\
(\sigma)\end{array}$ & $\begin{array}{l}10-11 \\
\left(\pi^{C}\right)\end{array}$ & $\begin{array}{c}10 \cdot 30 \\
\left(\pi^{N}, \mathrm{O}\right)\end{array}$ \\
\hline $4 \mathrm{OH} \cdot \mathrm{PNO}$ & MINDO/3 & $\begin{array}{c}8.55 \\
\left(\pi^{0}\right)\end{array}$ & $\begin{array}{l}9.87 \\
(\sigma)\end{array}$ & $\begin{array}{l}10-33 \\
\left(\pi^{\mathrm{C}}\right)\end{array}$ & $\begin{array}{c}11 \cdot 20 \\
(\sigma)\end{array}$ \\
\hline QNO** & MINDO/3 & $\begin{array}{c}7.99 \\
\left(\pi^{\mathrm{C}, 0}\right)\end{array}$ & $\begin{array}{c}9.56 \\
\left(\pi^{C}\right)\end{array}$ & $\begin{array}{l}9.66 \\
(\sigma)\end{array}$ & $\begin{array}{c}9.87 \\
\left(\pi^{\mathrm{O}, \mathrm{C}}\right)\end{array}$ \\
\hline $4 \mathrm{NO}_{2} \cdot \mathrm{QNO}$ & MINDO $/ 3$ & $\begin{array}{c}3.52 \\
\left(\pi^{\mathrm{C}, ~ O}\right)\end{array}$ & $\begin{array}{l}9 \cdot 72 \\
(\sigma)\end{array}$ & $\begin{array}{r}9.91 \\
\left(\pi^{\mathrm{C}}\right)\end{array}$ & $\begin{array}{c}10-07 \\
(\sigma)\end{array}$ \\
\hline
\end{tabular}

* $I_{i}(i=1-4)$ stands for the $i$ th ionisation energy from MINDO/3 calculations;

** Pyridine-N-oxide is designated as PNO, and quinoline-N-oxide as QNO.

Table 2. Population of nitrogen and oxygen atoms in the $\mathbf{N}$-oxide moiety.

\begin{tabular}{|c|c|c|c|c|c|c|c|c|}
\hline \multirow[b]{3}{*}{ Compounds* } & \multicolumn{8}{|c|}{ Population } \\
\hline & \multicolumn{4}{|c|}{$\mathbf{N}$} & \multicolumn{4}{|c|}{$\mathrm{O}$} \\
\hline & $s$ & $p_{x}$ & $p_{y}$ & $p_{z}$ & $s$ & $p_{x}$ & $p_{y}$ & $p_{z}$ \\
\hline Pyridine & 1.60 & $1 \cdot 10$ & $1 \cdot 32$ & $1 \cdot 13$ & & & & \\
\hline PNO & $1 \cdot 30$ & 099 & 1.00 & 1.05 & 1.94 & $1 \cdot 70$ & $1 \cdot 17$ & 1.84 \\
\hline $4 C N \cdot P N O$ & $1 \cdot 27$ & $0-99$ & $0-98$ & $1 \cdot 03$ & 1.92 & 1.68 & $1 \cdot 24$ & $1 \cdot 79$ \\
\hline $4 \mathrm{NO}_{2} \cdot \mathrm{PNO}$ & $1 \cdot 27$ & $0-99$ & 0.98 & 0.99 & 1.92 & 1.69 & $1 \cdot 24$ & 1.77 \\
\hline $4 \mathrm{NH}_{2} \cdot \mathrm{PNO}$ & $1 \cdot 27$ & 0.98 & $0-98$ & 1.09 & 1.92 & 1.68 & 1.23 & 1.83 \\
\hline $4 \mathrm{OH} \cdot \mathrm{PNO}$ & $1 \cdot 27$ & 0.99 & 0.98 & 1.09 & 1.92 & 1.67 & $1 \cdot 23$ & $1 \cdot 82$ \\
\hline QNO & $1 \cdot 30$ & 0.99 & $0-97$ & 1.04 & 1.92 & 1.73 & 1.21 & 1.77 \\
\hline $4 \mathrm{NO}_{2} \cdot \mathrm{QNO}$ & $1 \cdot 30$ & $0-99$ & $0-98$ & 0.97 & 1.91 & 1.71 & $1 \cdot 27$ & 1.71 \\
\hline
\end{tabular}

- Abbreviations as in table 1.

\subsection{Nature of the $N$-oxide bond}

It is evident from table 2 , that in all these $\mathrm{N}$-oxides, the typical hybridisation on the oxygen atom of the $\mathrm{N}$-oxide moiety is $s^{\approx 1.9} p^{\approx 2.9}$. There is almost an entire lone pair of electrons in the $p_{2}$ orbital (which is perpendicular to the plane of the ring) of the oxygen atom in the $\mathrm{N}$-oxide fragment. So for all practical purposes, the $\mathrm{N}-\mathrm{O}$ bond in the 
$\mathrm{N}$-oxide moiety is more of a single bond than a double bond. This is in contrast to the earlier observation of Kulkarni et al (1981), where this bond. was predicted to be fairly close to a double bond.

The mode of hybridisation of nitrogen $\left(s^{\approx 1.6} p^{\approx 2.41}\right)$ in pyridine however changes to $s^{\approx 1.3} p^{\approx 1.96}$ in the pyridine-N-oxide. This may be traced to the higher electronegativity of the oxygen atom.

It is interesting to note that the 'NO' bond of the N-oxide moiety is different from that in an $-\mathrm{NO}_{2}$ group. In the latter the $p_{2}$ electrons are more delocalised to give the $\mathrm{NO}$ bond an appreciable $\pi$-bond character.

\subsection{Antifungal activity}

It has been suggested from experimental studies on these antifungal nitro-compounds that the mode of action involves interference with either a sulphydryl enzyme or the nitro-reduction system of the micro-organism (Fukui et al 1960). Amongst the compounds listed in table 3, 4-nitroquinoline- $\mathrm{N}$-oxide has the highest antifungal activity followed by 4 -nitropyridine- $\mathrm{N}$-oxide. It is important to note that dinitroquinoline- $\mathrm{N}$-oxide does not have the activity.

To answer the various questions associated with antifungal activity, a systematic examination of the effects of attaching an oxygen atom to the nitrogen of the ring, and also of introducing a nitro group at the fourth position in the ring, is of prime importance.

So far as the energy of the lowest unoccupied molecular orbital (LUMO) gives a measure of the electron accepting ability of these molecules, the simple $\mathrm{N}$-oxides are better $\pi$-acceptors (and accordingly more reactive towards nucleophiles) than the parent compounds. Thus pyridine- $\mathrm{N}$-oxide is more reactive towards nucleophiles as compared to pyridine (table 3). Also, on comparing the energy of the Lumo of pyridine,

Table 3. Energies* of HOMO and LuMO of substituted N-oxides.

\begin{tabular}{|c|c|c|}
\hline \multirow[b]{2}{*}{ Compound } & \multicolumn{2}{|c|}{ Energy $(\mathrm{eV})$} \\
\hline & номо & LUMO \\
\hline Pyridine (Py) & $-9 \cdot 17$ & $1 \cdot 26$ \\
\hline $4 \mathrm{NO}_{2} \cdot \mathrm{Py}$ & -9.90 & -0.26 \\
\hline PNO & -9.01 & 0.45 \\
\hline $4 \mathrm{NO}_{2} \cdot \mathrm{PNO}$ & $-9 \cdot 71$ & -0.73 \\
\hline $4 \mathrm{CN} \cdot \mathrm{PNO}$ & -8.95 & 0.18 \\
\hline $4 O H \cdot$ PNO & $-8 \cdot 55$ & $0-26$ \\
\hline $4 \mathrm{NH}_{2} \cdot \mathrm{PNO}$ & -8.04 & $0-49$ \\
\hline Quinoline & $-8 \cdot 16$ & $0-23$ \\
\hline QNO & -7.99 & -0.14 \\
\hline $4 \mathrm{NO}_{2} \cdot \mathrm{QNO}$ & -8.52 & -0.75 \\
\hline Dinitroquinoline-N-oxide & -8.91 & $-1 \cdot 31$ \\
\hline
\end{tabular}

* For pyridine and $4 \mathrm{NO}_{2} \cdot$ pyridine the HOMO are of the $\sigma$-type while they are of the $\pi$-type for the remaining compounds. However, for the sake of comparison, the energy of $\pi$-номо of these compounds are shown in the table. The Lumo on the other hand are all $\pi$-type. 
pyridine-N-oxide and 4-nitropyridine, it is obvious that the introduction of a nitrogroup at the $\mathrm{C}(4)$ position has made 4-nitropyridine a better electron acceptor than pyridine and pyridine-N-oxide. It is thus apparent that the combined effect of $\mathrm{N}$-oxidation and introduction of a nitro-group at the $\mathrm{C}(4)$ position is to make the compound more reactive towards nucleophiles. Thus, 4-nitropyridine- $\mathrm{N}$-oxide is the best $\pi$-acceptor amongst all the pyridine compounds listed in table 3 . For the same reason 4-nitroquinoline- $\mathrm{N}$-oxide is a better electron acceptor than quinoline and quinoline-N-oxide.

We now find a correlation between the ability to accept electrons and the antifungal activity. The two powerful antifungal agents, 4-nitroquinoline- $\mathrm{N}$-oxide and 4-nitropyridine- $\mathrm{N}$-oxide are good $\pi$-acceptors. The $\mathrm{C}(4)$ atoms in $4-\mathrm{NO}_{2} \cdot \mathrm{PNO}$ and $4 \mathrm{NO}_{2} \cdot$ QNO-quinoline- $\mathrm{N}$-oxide) have the highest frontier (LUMO) electron density amongst the $\mathrm{C}$-atoms in the respective molecules and hence are the most probable sites for nucleophilic attack by the $\mathrm{SH}^{-}$group. Of these two compounds $4 \mathrm{NO}_{2} \cdot \mathrm{QNO}$ is a more potent antifungal agent than 4- $\mathrm{NO}_{2} \cdot \mathrm{PNO}$. Unfortunately, the energies of the LUMo of these compounds are quite comparable and hence not of much help in understanding their relative order of activity as antifungal agents. As optimisation of bond parameters vas not carried out, the extent to which the energies of the Lumo can account for the relative order of activity remains indeterminate.

It is interesting to note that comparison of nucleophilic superdelocalizability of the $\mathrm{C}(4)$ atom in 4-NO $\mathrm{N}_{2} \cdot \mathrm{PNO}$ and in $4-\mathrm{NO}_{2} \cdot \mathrm{QNO}$ could not provide support to Fukui et al (1960).

Since the antifungal activities of these $\mathrm{N}$-oxides appear to be due to their ability to accept electrons, one may wonder why dinitroquinoline- $\mathrm{N}$-oxide, the most powerful electron acceptor in the series (table 3 ) does not show antifungal activity. The nonactivity of dinitroquinoline- $\mathrm{N}$-oxide may be traced to the fact that this compound, being an extremely powerful oxidising agent, gets destroyed before reaching the appropriate enzyme site.

\section{Conclusion}

In conclusion, it may be said that the antifungal activities of these nitro-aromatic $\mathrm{N}$-oxides depend on their ability to act as good electron acceptors. The $\mathrm{SH}^{-}$attacks the $\mathrm{C}(4)$ atom, which has the highest frontier electron density (LUMO) in the respective molecules. No simple relation between antifungal activity and superdelocalizability could be obtained.

\section{References}

Bingham R C, Dewar M J S and Lo D H 1975 J. Am. Chem. Soc. 971285

Dodd M C and Stillman W B 1944 J. Pharmacol. Exp. Theor. 8211

Eichhorn G L 1956 Acta Crystallogr. 9787

Fukui K, Imamura A and Nagata C 1960 Bull. Chem. Soc. Jpn 33122

Kulkarni G V, Ray A and Patel C C 1981 J. Mol. Struct. 71253

Maier J P and Muller J F 1974 J. Chem. Soc. Faraday Trans. 270

Ochiai E 1967 Aromatic amine oxides (Amsterdam: Elsevier)

Ulku D, Huddle B P and Marrow J C 1971 Acta Crystallogr. B27 432

Weiner M A and Lattman M 1974 Tetrahedron Lett. 1709 